\title{
An Investigation on the Influence of Teachers' Feedback on Learners' Anxiety in English Classroom
}

\author{
Min HUA \\ School of Foreign Languages, Wuhan Textile University, Wuhan, 430073, China \\ email: Rebecca_huamin@126.com
}

Key words: Learner's Anxiety; Teachers' feedback; English classroom; Evaluation

\begin{abstract}
With the results of the qualitative and quantitative researches, the author finds out that: Foreign language anxiety exists among Chinese English learners in the setting of classroom, varying in their anxiety degree. Teachers' questioning and feedback do cause anxiety to learners. Learners with high, moderate and low anxiety have different requirements to teachers' questioning and feedback. Results show that learners with high and moderate anxiety prefer referential questions for it is less anxiety-provoking than display ones, while learners with low anxiety have negative attitude toward study. Teachers should be aware of the necessity of creating a non-threatening and less anxiety-provoking environment for the learners’ English learning.
\end{abstract}

\section{Introduction}

Since the 1970s, the focus on English learning and teaching has been shifted from the way the teacher teaches to the way the learner learns, owing to the development of humanistic psychology and the exploration of the second language acquisition. [1] More and more teachers and researchers pay increased attention to learners' affective variables. Anxiety, as one of the most important affective variables, has prevailed in Foreign Language Learning and it attracts more and more academic concerns of foreign or second language teaching worlds. [2] A large number of previous studies show that anxiety is possibly the most pervasive obstruction in second/foreign language learning and the relationship between anxiety and performance is an inverted-U relationship. [3] Too high or too low anxiety will have a bad effect on study. Therefore, discussions on how to help learners moderate their English classroom anxiety to improve their learning efficiency possess both theoretical significance and practical value. [4] [5] It is hoped that the suggestions mentioned above can provide useful information for language teachers to become aware of the foreign language anxiety and to modify their instructional techniques so that the learners may benefit from the low anxiety-provoking language learning situations in the classroom.

\section{Methodology}

\section{A. Research Questions}

a. Will teacher's question cause any anxiety to learners?

b. If it will, what are the learners' preferences toward questioning types and wait time with regarding to moderating anxiety?

\section{B. Subjects}

This study has made the survey for freshmen of Grade 2014 studying in Wuhan Textile University who are not majoring in English. A total of 220 questionnaires for learners were collected, of which 200 were considered valid for the purpose of the statistical analysis. A total of 35 questionnaires for teachers were collected, of which 30 were considered valid.

\section{Instruments}

A questionnaire called the Foreign Language Classroom Anxiety Scale(FLCAS), which is developed by Horwitz and Cope. The first questionnaire was composed of the following contents: personal information and Foreign Language Classroom Anxiety Scale( FLCAS). The second one was designed on my own with a view to understand learners' anxiety status by combining teachers' 
questions and feedbacks after referring to some related information. The third one was used to be aware of Chinese teachers' frequently-adopted methods about questioning and feedback and learners' suggestions to teachers' questioning and feedback.

\section{Date collection}

In the first step, the author has employed a research instrument: a questionnaire called the Foreign Language Classroom Anxiety Scale (FLCAS), which is developed by Horwitz and Cope The researcher handed out these questionnaires to learners and asked them to answer 33 questions based on their actual situation. [5] Then the researcher divided these learners into three groups: high-anxiety, mid-anxiety and low-anxiety groups according to their overall performance on the FLCAS. In the second step: the author has used the other two research instruments : 1)a questionnaire called scale on Teacher's Question, Feedback and Learners' Anxiety, which was designed by the author herself after referring to some related papers. When the learners completed these questions, the researcher collected them. On the one hand, the researcher could find out the correlations between learners' anxiety and teacher’s questions and feedback through SPSS.

\section{Results and Data Analysis}

Table 1 Number of Subjects for Questionnaire

\begin{tabular}{cccc}
\hline $\begin{array}{c}\text { Questionnaires } \\
\text { handed out }\end{array}$ & $\begin{array}{c}\text { Collected back } \\
\text { (number) }\end{array}$ & Valid numbers & Validity rate \\
\hline 220 & 208 & 200 & $90 \%$ \\
\hline
\end{tabular}

Table 1 shows the number of the questionnaires which have been handed out to the learners as well as the number of questionnaires which are validly completed and returned.

According to Horwitz, the theoretical scores of anxiety should be between 165 and 33 . The higher the number is, the less anxiety the learners will experience (1986). The mean of the subject

learners' scores of FLCAS in previous study is 96.7 by Aida (1994), and 97.79 by Liao(1999).The mean of the subjects' scores of the present study is 104.72. This indicates that the English learning anxiety in my study is a little bit less severe than that of other participants.

Table 2 Overview of Anxiety Level

\begin{tabular}{cccccc}
\hline & $\mathrm{N}$ & Range & Minimum & Maximum & Mean \\
\hline Anxiety & 200 & 78 & 64 & 142 & 104.72 \\
\hline
\end{tabular}

Table 2 shows that a great number of learners experience anxiety. In order to have a comprehensive and profound study of learners' anxiety state, the researcher distinguished the high-anxious learners from the low-anxious learners by checking all respondents' answers to the questionnaires. To put these learners investigated into three different anxiety groups in a more reasonable way, the author adopted the method for determining group membership devised by Ganschow and Sparks (1996). Firstly the author collected the data and calculated the mean of the answer given by each learner based on 33 items of the questionnaire. The author then puts these means into computer and uses SPSS to get the descriptive statistics.

Table 3 One-Sample Statistics of FLCAS

\begin{tabular}{ccccc}
\hline Anxiety level & No & Mean & Std. Deviation & Std. Error \\
\hline & 200 & 3.1731 & .39616 & .02801 \\
\hline
\end{tabular}

The table shows that the group's mean for all the questions is 3.17 and the standard deviation is about 0.4. Based on the results, we adopt the method for determining group membership devised by Ganschow and Sparks (1994). Based on the mean, we determine the degree to which learners deviated from the mean. The deviation of the highest score (or the least anxious learner) from the mean is +1.1 and the deviation of the lowest score from the mean is -1.3. Learners scoring one or more standard deviations above overall mean are identified as high-anxiety group; and those between +.4 and -.4 standard deviations from the mean are identified as mid-anxiety group; and those with one or more standard deviations below the mean are identified as low-anxiety group. Table 4.4 presents the number and percentage of learners in each anxiety category and the mean anxiety level and range for each identified group. 
Table 4 Number and Percentage of learners Identified in Each Anxiety Category

\begin{tabular}{ccc}
\hline Anxiety Category & Number & Percentage \\
\hline Low-anxiety & 42 & $21 \%$ \\
Mid-anxiety & 131 & $65.5 \%$ \\
High-anxiety & 27 & $13.5 \%$ \\
\hline
\end{tabular}

Table 4 shows that 42 respondents are classified as low-anxiety group, which accounts for $21 \%$, and 27 learners are classified as high-anxiety group, which accounts for 13.5\%. 131 of the 200 learners who answered the questionnaire (65.5\%) are classified as mid-anxiety group when learning a foreign language.

\section{Descriptive Statistics of Questionnaire on Teachers' and Learners' Attitudes toward Classroom Questioning and Feedback}

In order to have a comprehensive analysis, the author also designed the third questionnaires including many multiple choices for teachers and learners to choose from after referring to related information. The questionnaires were handed out for 35 teachers and 30 were regarded valid. The following tables are the investigated results.

Table 5 Questionnaire for Teachers

\begin{tabular}{cccccccc}
\hline & & & & & \multicolumn{2}{c}{ Total } \\
Question No & $\mathrm{A}$ & $\mathrm{B}$ & $\mathrm{C}$ & $\mathrm{D}$ & $\mathrm{E}$ & $\mathrm{F}$ & Number(\%) \\
\hline 1 & $75 \%$ & $20 \%$ & $5 \%$ & $0 \%$ & $0 \%$ & $0 \%$ & 100 \\
2 & $70 \%$ & $30 \%$ & $0 \%$ & $0 \%$ & $0 \%$ & $0 \%$ & 100 \\
3 & $28 \%$ & $72 \%$ & $0 \%$ & $0 \%$ & $0 \%$ & $0 \%$ & 100 \\
4 & $33 \%$ & $67 \%$ & $0 \%$ & $0 \%$ & $0 \%$ & $0 \%$ & 100 \\
5 & $11 \%$ & $80 \%$ & $9 \%$ & $0 \%$ & $0 \%$ & $0 \%$ & 100 \\
6 & $7 \%$ & $10 \%$ & $73 \%$ & $0 \%$ & $0 \%$ & $0 \%$ & 100 \\
7 & $2 \%$ & $98 \%$ & $0 \%$ & $0 \%$ & $0 \%$ & $0 \%$ & 100 \\
8 & $64 \%$ & $11 \%$ & $13 \%$ & $10 \%$ & $0 \%$ & $0 \%$ & 100 \\
9 & $30 \%$ & $50 \%$ & $20 \%$ & $0 \%$ & $0 \%$ & $0 \%$ & 100 \\
10 & $35 \%$ & $65 \%$ & $0 \%$ & $0 \%$ & $0 \%$ & $0 \%$ & 100 \\
\hline
\end{tabular}

Table 5 shows that 75\% English teachers attach great importance to questioning in classroom, and the majority of investigated English teachers (70\%) take learners' affective factors into consideration during their classroom activities. To the amazement of the researcher, most of the English teachers are not clear about different questioning styles and error correction types. 72\% teachers do not know the terms like "display and referential questions" and 98\% teachers could not tell the differences between recast and negotiation of form. Statistics show that $67 \%$ teachers prefer to ask closed questions and only 33\% teachers would like to propose open ones. When being asked their questioning strategies, $80 \%$ express that they often propose the questions then name a learner to answer. The results show that most of the teachers choose to encourage their learners no matter whether their answers are right or wrong.

Table 6 Questionnaire for Learners

\begin{tabular}{lllllllll}
\hline $\begin{array}{l}\text { Question } \\
\text { No }\end{array}$ & A & B & C & D & E & F & $\begin{array}{c}\text { Total number } \\
(\mathbf{1 0 0 \% )})\end{array}$ \\
\hline 1 & $76 \%$ & $24 \%$ & $0 \%$ & $0 \%$ & $33 \%$ & $67 \%$ & 100 & \\
2 & $5 \%$ & $53 \%$ & $34 \%$ & $8 \%$ & $0 \%$ & $0 \%$ & 100 \\
3 & $25 \%$ & $0 \%$ & $0 \%$ & $75 \%$ & $0 \%$ & $0 \%$ & 100 & \\
4 & $25 \%$ & $65 \%$ & $10 \%$ & $0 \%$ & $0 \%$ & $0 \%$ & 100 \\
5 & $6 \%$ & $22 \%$ & $72 \%$ & $0 \%$ & $0 \%$ & $0 \%$ & 100 \\
\hline
\end{tabular}

Table 6 is a questionnaire about learners' suggestions to teachers' questioning, error correction and evaluation. Item 1 shows that most of the learners would like to answer open and divergent questions. This is in coincidence with my interview. From the result of item 2, we can see that only $5 \%$ of the learners choose interruption and explicit error correction and only $8 \%$ of the learners hope the teacher could ignore their errors. Most of them prefer implicit error correction. Item 3 and 4 are to examine learners' suggestion to teachers' teaching style and wait time. From the results, we 
can see that a great number of learners prefer group discussion and longer wait time. The last item is about learners' suggestion to teachers' evaluation. The result has obviously shown that nearly all the learners welcome teachers' positive evaluation. $72 \%$ learners hope the teacher could point out their progress and offer praise.

\section{Conclusion}

The results and data analysis of chapter four helps us to draw the conclusion: most of which are in coincidence with the results we get from the questionnaire. There exists a certain level of correlation between learners' classroom anxiety and teacher's question and feedback. Most of the learners from three different anxious-level groups would feel anxious while waiting for teacher's questions and feedback. Most of Chinese teachers have taken learners' affective factors into consideration; however they do not have sufficient knowledge about effective ways to moderate learners' anxiety. Our questionnaires show that the majority of English teachers tend to ask display questions and explicit error correction. Therefore, it is of great significance for foreign language department to hold related training courses for non-English major teachers to improve their methods of questioning and error correction.

\section{References}

[1] Laura Gurzynski-W eiss, Andrea Révész. Tasks, Teacher Feedback, and Learner Modified Output in Naturally Occurring Classroom Interaction [J]. Language Learning. 2012 (3)

[2] John Bitchener,Ute Knoch. The Contribution of Written Corrective Feedback to Language Development: A Ten Month Investigation [J]. Applied Linguistics. 2010 (2)

[3] Rupert Wegerif. Dialogic or dialectic? The significance of ontological assumptions in research on educational dialogue [J]. British Educational Research Journal. 2008 (3)

[4] Suzanne Hidi. Interest: A unique motivational variable [J]. Educational Research Review.2006 (2)

[5] John Bitchener. Evidence in support of written corrective feedback [J]. Journal of Second Language Writing. 2007 (2) 